\title{
REVISÃO ESTRATIGRÁFICA DA BACIA DOS PARECIS - AMAZÔNIA
}

\author{
RUY B. C. BAHIA ${ }^{1}$, MARCELO A. MARTINS-NETO ${ }^{2}$, MARIA SILVIA C. BARBOSA ${ }^{3} \&$ \\ AUGUSTO J. PEDREIRA ${ }^{4}$
}

\begin{abstract}
Resumo A Bacia dos Parecis está localizada na região centro-oeste do Brasil, na porção sudoeste do Cráton Amazônico, entre os cinturões de cisalhamento Rondônia e Guaporé. Está dividida, de oeste para leste, em três domínios tectono-sedimentares:o extremo oeste é uma depressão tectônica, a porção central é um baixo gravimétrico e o extremo leste é uma bacia interior tipo "sag". Durante Paleozóico (do Ordoviciano ao Eo-Permiano) a região Amazônica foi afetada por um evento extensional, quando foram depositados, na Bacia dos Parecis, as formações Cacoal, Furnas, Ponta Grossa, Pimenta Bueno e Fazenda da Casa Branca. A Formação Cacoal é composta de conglomerados, rochas sedimentares líticas, folhelhos e dolomitos, interpretados como depositados em leques aluviais, deltas e lagos. Os ambientes deposicionais das formações Furnas e Ponta Grossa, compostas respectivamente de arenito com seixos e folhelho, são interpretados como de planície de maré e marinho, respectivamente. Os conglomerados, folhelhos e arenitos da Formação Pimenta Bueno, e conglomerados, arcóseos e folhelhos da Formação Fazenda da Casa Branca são interpretados como glacial ou periglacial. Desde o Permiano ao Triássico existe um "gap" no registro estratigráfico da Bacia dos Parecis. Sucessão de rochas vulcânicas e sedimentares mesozóica registra outro evento extensional na região Amazônica. Este evento está representado na Bacia dos Parecis pelos arenitos eólicos jurássicos da Formação Rio Ávila e basaltos das formações Anarí e Tapirapuã. No Cretáceo os arenitos e conglomerados do Grupo Parecis, foram depositados em ambientes fluvial e eólico. Corpos kimberlíticos do Cretáceo cortam os sedimentos nas porções noroeste e sudeste da bacia. Areia, silte e argila cenozóicos cobrem discordantemente os depósitos da Bacia dos Parecis.
\end{abstract}

Palavras-chave: Estratigrafia, evolução de bacias, Bacia dos Parecis.

Abstract STRATIGRAPHIC REVIEW OF THE PARECIS BASIN, AMAZONIAN REGION. The Parecis basin is located in central-western Brazil, on the southwestern part of the Amazon Craton, between the Rondônia and Guaporé fold belts. From west to east, the Parecis basin can be divided into three tectono-sedimentary domains: a tectonic low to the west, a central compartment characterized by a negative gravimetric anomaly, and a interior sag to the east. During the Paleozoic (Ordovician to Early Permian), the Amazon region was affected by an extensional event, when the Cacoal, Furnas, Ponta Grossa, Pimenta Bueno e Fazenda da Casa Branca formations were deposited in the Parecis basin. The Coacal Formation is composed of conglomerates, wackes, shales and dolomites, interpreted as deposited in alluvial fans, deltas and lakes. The pebbly sandstones and shales of the Furnas and Ponta Grossa formations are interpreted as deposited, respectively, in tidal flats and marine environments. Glacial or glacial-influenced environments are suggested for the conglomerates, sandstones and shales of the Pimenta Bueno and Fazenda da Casa Branca formations. The sedimentary record of Parecis basin shows a stratigraphic gap from Permian to Triassic. Mesozoic volcanic and sedimentary successions record another extensional event in the Amazon region. This event is represented in the Parecis basin by the eolian sandstones of the Jurassic Rio Ávila Formation and the basalts of the Anarí and Tapirapuã formations. The sandstones of the Parecis Group have been deposited during the Cretaceous in fluvial and eolian environments. Cretaceous kimberlite bodies cut the sediments in the northeastern and southeastern parts of the Parecis basin. Cenozoic sandstones and mudstones cover unconformably the deposits of the Parecis basin.

Keywords: Stratigraphy, basin evolution, Parecis basin, Brazil.

INTRODUÇÃO A Bacia dos Parecis é uma das maiores bacias intracratônicas brasileiras. Está localizada na região Centro-Oeste, entre as bacias do Solimões, Alto Tapajós e Paraná, na região "foreland" da Cordilheira dos Andes (figuras 1A e 1B). Cobre uma área de $500.000 \mathrm{~km}^{2}$ nos estados de Rondônia e Mato Grosso, acumulando mais de $6.000 \mathrm{~m}$ de sedimentos paleozóicos, mesozóicos e cenozóicos, essencialmente siliciclásticos. Ocupa a porção sudoeste do Cráton Amazônico, entre os cinturões de cisalhamento Rondônia e Guaporé. Os limites sudeste e nordeste da bacia são os arcos do Xingu (Almeida, 1983) e Rio Guaporé, respectivamente.

O mapeamento geológico da bacia ao nível de reconhecimento (escala 1:250.000), realizado pelo Departamento Nacional da Produção Mineral - DNPM, foi conduzido na década de 70 pela Companhia de Pesquisa de Recursos Minerais - CPRM: a porção oeste pelo Projeto Sudeste de Rondônia (Pinto Filho et al.,1977), a porção central e nordeste pelo Projeto Centro-Oeste do Mato Grosso (Padilha et al.,1974), a porção sudoeste pelo Projeto Serra do Roncador (Costa et al.,1975) e a cunha sudeste da bacia pelos projetos Alto Guaporé e Serra Azul (Barros \& Pastore Jr.,1974 e Ribeiro Filho et al.,1975, respectivamente). Siqueira (1989) integrou as informações dos mapeamentos geológicos com dados de geofísica obtidos por outros autores, publicando uma síntese sobre a Bacia dos Parecis.

Dentre as rochas sedimentares da bacia, supostamente depositadas em ambiente continental, existem folhelhos carbonosos e radioativos, possíveis geradores de hidrocarbonetos (Siqueira, 1989), fato que levou a Petróleo Brasileiro S.A.-PETROBRAS a pesquisar hidrocarbonetos na bacia. Entretanto somente dois furos de sonda foram perfurados: o primeiro pela CPRM para pesquisa de carvão energético e o segundo pela PETROBRAS, para hidrocarbonetos.

1 - CPRM - Serviço Geológico do Brasil CPRM - REPO (Residência de Porto Velho) Av. Lauro Sodré, 2561 - Bairro dos Tanques, Porto Velho, Rondônia - CEP: 78.904 - 300 - E-mail: ruybahia@pv.cprm.gov.br

2 - Universidade Federal de Ouro Preto - UFOP - Escola de Minas - Departamento de Geologia - DEGEO - Campus Morro do Cruzeiro, S/N, Ouro Preto, Minas Gerais - CEP: 35.400 .000 - E-mail: marcelo@nupetro.com.br

3 - Universidade Federal de Ouro Preto - UFOP - Escola de Minas - Departamento de Geologia - DEGEO - Campus Morro do Cruzeiro, S/N, Ouro Preto, Minas Gerais - CEP: 35.400.000 - E-mail: silvia@nupetro.com.br

4 - CPRM - Serviço Geológico do Brasil - CPRM - Superintendência de Salvador - Sureg-SA - Av. Ulisses Guimarães, N0 2862 - Salvador - Bahia - CEP: 41.213 -000 - E-mail: ajpedreira@terra.com.br 


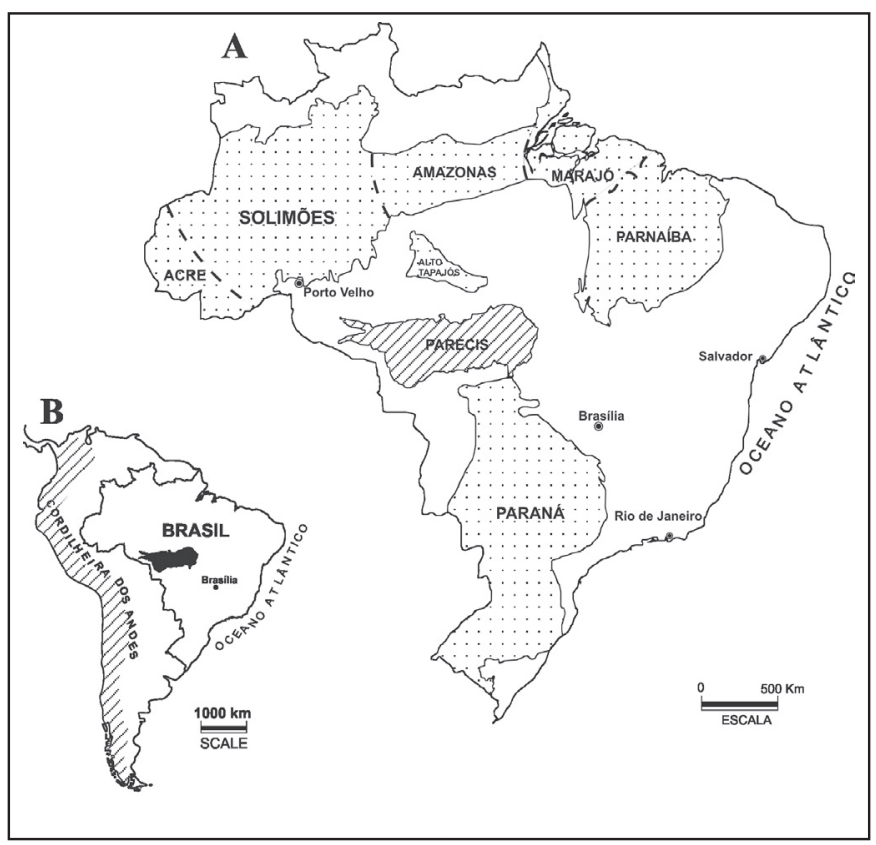

Figura 1 - Mapa de situação da Bacia dos Parecis

O presente trabalho objetiva, de forma inédita, integrar a evolução tectonossedimentar da Bacia dos Parecis. A nomenclatura segue aquela apresentada por Siqueira (1989), e a descrição e interpretação das várias unidades litoestratigráficas apresentadas detalhadamente nos diversos trabalhos previamente citados, bem como dados coletados pelos autores.

ESTRATIGRAFIA O mapa geológico da bacia (figura 2) foi compilado e modificado de Siqueira (1989) e Bizzi et al (2003), para mostrar aproximadamente a distribuição superficial de algumas unidades litoestratigráficas não cartografadas individualmente em seus mapas.

Embasamento O embasamento da Bacia dos Parecis é constituído de rochas do Cráton Amazônico. Compreende rochas de alto e baixo grau metamórfico, rochas metassedimentares, bem como rochas intrusivas. Na figura 2 o perfil esquemático mostra a relação do pacote sedimentar com o embasamento cristalino.

As primeiras são os granulitos do Complexo Jamarí no Estado de Rondônia (oeste da bacia) e os gnaisses, migmatitos e granitóides do Complexo Xingu (norte e sul da bacia) de idade arqueana e mesoproterozóica, nos estados do Mato Grosso e Goiás. As rochas metassedimentares afloram na porção sudeste da bacia, também nos estados do Mato Grosso e Goiás As rochas intrusivas básicas e ultrabásicas estão relacionadas ao Mesoproterozóico (figura 3).

Rochas Sedimentares A Carta Estratigráfica da Bacia dos Parecis (Siqueira,1989; Bahia \& Pedreira,1996; Bahia et al.1996) mostrada na figura 4, apresenta as unidades sedimentares que ocorrem na Bacia, uniformizando a nomenclatura estratigráfica utilizada em trabalhos anteriores. Alguns intervalos estratigráficos não apresentam unidades, colocando algumas formações em contato erosivo entre si, em inconformidade, bem como evidencia os principais hiatos e discordâncias.

Os dados obtidos na literatura em relação a algumas formações não são uniformes. Entretanto, os projetos a partir dos quais eles foram coletados tinham escalas uniformes (1:250.000), o que permitiu, em conjunto com os dados obtidos pelos autores, a integração das informações. Em alguns casos, espessuras foram estimadas tendo em vista variabilidades na qualidade e acesso aos afloramentos. Por estas razões, existem vários problemas de correlação intrabacial.

FORMAÇÃO CACOAL - NEO-ORDOVINCIANO (Siqueira 1989) Esta formação aflora nas vizinhanças do centro de Cacoal (figura 2) e foi atravessada em sondagem rasa para pesquisa de calcário e sondagem profunda para exploração de carvão, anteriormente mencionada. A primeira na região de Presidente Médici, e a segunda a $70 \mathrm{~km}$ a sudeste de Pimenta Bueno, a Formação Cacoal (Figura 5) é constituída de conglomerado, argilito dolomítico, arenito conglomerático e feldspático, siltito e folhelho.

Os conglomerados basais da Formação Cacoal são polimíticos com matriz arcoseana; os clastos são angulosos com mais de um metro de diâmetro, sendo de várias composições: rochas básicas e ultrabásicas, rochas vulcânicas ácidas, gnaisses, cataclasitos e metassiltitos. Os argilitos que acompanham os conglomerados são dolomíticos e estão intercalados com siltitos carbonáticos e brechas intraformacionais com cimento ferruginoso.

A porção intermediária da formação compreende uma alternância de folhelhos, arenitos e arcóseos (arenitos feldspáticos). Entre o centro de Cacoal e Pimenta Bueno os arenitos ocorrem em forma de lobos amalgamados ou em alternância de dimensões métricas com folhelho, mostrando a base deformada nas camadas de arenito e paleocorrentes para nordeste, sudoeste e oeste. No topo da formação, os dolomitos argilosos contém nódulos silicosos e um pouco de gipsita.

Considerando o tamanho e forma dos clastos e imaturidade da matriz, os conglomerados são interpretados como depositados em leques aluviais, em condições de clima árido. Os arenitos feldspáticos depositados em formas de lobos e a alternância de folhelho e arenito na porção intermediária da formação parecem ter sido depositados em ambiente deltaico.

A intercalação de argilito, bancos de dolomito, com alto teor de magnésio e níveis de gipsita pode ser interpretada como depositada em planície de maré, também em clima árido. Esta seqüência pode ser comparada com o modelo apresentado por Frostick e Reid (1987) para o preenchimento de riftes.

Com base no furo PB-20-RO do Projeto Presidente Hermes (Freitas,1978), o contato inferior da Formação Cacoal é com os siltitos silicificados da Formação Mutum-Paraná (Lobato, 1966), relacionada ao Paleoproterozóico, com idade de 1751 $\mathrm{Ma}(\mathrm{U}-\mathrm{Pb})$ ou com o Complexo Jamari, correspondente ao embasamento cristalino regional, relacionado ao Paleoproterozóico, com idade de $1761 \mathrm{Ma}(\mathrm{U}-\mathrm{Pb})$.

O contato superior é com a Formação Pimenta Bueno, marcado no furo PB-1-RO do Projeto Carvão (Soeiro,1981), onde é caracterizado como um contato erosivo do dolomito, que encerra o pacote sedimentar da Formação Cacoal, com o diamictito da base da Formação Pimenta Bueno.

Siqueira (1989) correlacionou a Formação Cacoal com as porções superiores da Formação Rio Ivaí e intermediária da Formação Vila Maria da Bacia do Paraná. Sua espessura mínima foi estimada por este autor em 230 metros.

FORMAÇÃO FURNAS - EODEVONIANO (Oliveira, 1912) A Formação Furnas (Oliveira,1912) foi descrita na Bacia do Paraná (figura1). Na Bacia dos Parecis, as exposições estão no canto sudeste (figura 2), nas escarpas da Serra do Roncador, constituída somente de conglomerado e arenito seixoso. Esta formação começa com arenito conglomerático, com acamamento plano-paralelo, nos quais ocorrem seixos angulosos a subarredondados, com baixa esfericidade e diâmetros acima de 5 centímetros (Figura 6).

Ao longo da rodovia que liga Água Boa a Ribeirão Casca- 


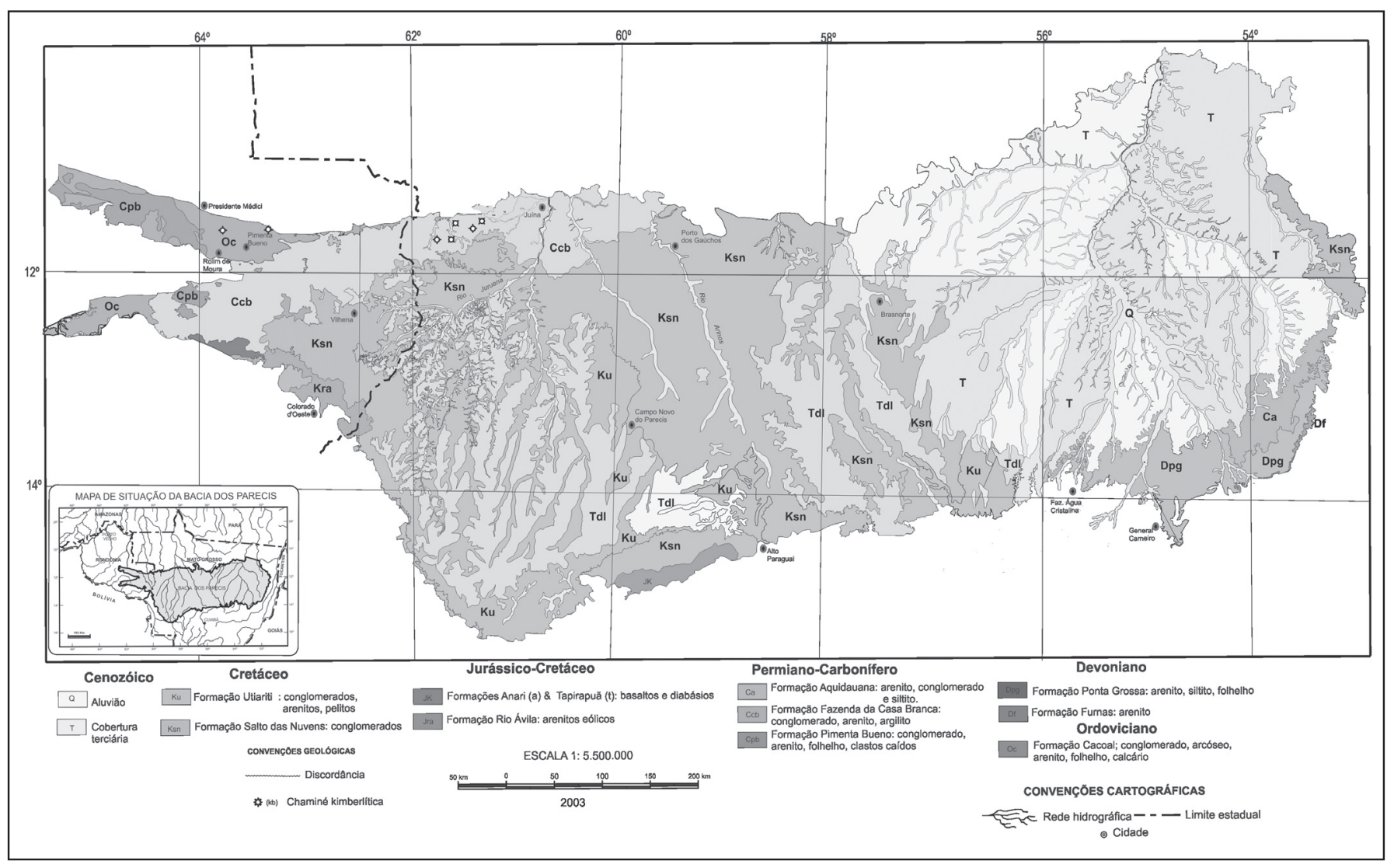

Figura 2- Seção geológica esquemática da Bacia dos Parecis.

lheira esta formação apresenta excelentes exposições, com presença de arenito conglomerático, ferruginoso, e estruturas convolutas. É excepcional a presença de icnofósseis.

Não existem informações seguras com relação à variação na espessura da formação. Na Fazenda 7 de Setembro, segundo Costa et al.(1975), a espessura da formação é de 11 metros. O contato inferior da Formação Furnas é com o embasamento cristalino e o contato superior é gradacional com a Formação Ponta Grossa.

O ambiente deposicional na Bacia dos Parecis é fluvial, porém, segundo Ciguel et al.1996, observações na Bacia do Paraná sugerem um ambiente marinho raso (planície de maré) para esta formação.

FORMAÇÃO PONTA GROSSA - NEODEVONIANO (Oliveira, 1912) A Formação Ponta Grossa foi descrita pela primeira vez por Oliveira (1912), na Bacia do Paraná (figura 1). Na Bacia dos Parecis aflora no canto sudeste, norte e nordeste de General Carneiro, no Planalto do Roncador (figura 2). É constituída de arenito, siltito e folhelho (Figura 7).

Ao longo da rodovia que liga Água Boa a Ribeirão Cascalheira esta formação apresenta excelentes exposições, com seções apresentando uma intercalação de siltito e arenito muito fino, segundo uma seqüência de cores preta e amarela, separados por níveis lateritizados, definindo uma estratificação planoparalela ou mergulhando $5^{0}$ para norte. O topo da formação é uma seqüência de 10 metros de espessura de folhelho marrom. Para o sudoeste, na região de General Carneiro, segundo Ribeiro Filho et al.(1975), a formação consiste de folhelhos verdes finamente laminados, arenitos finos e grossos, com acamamento cruzado, localmente arenito conglomerático.

O contato basal da formação é gradacional com a Formação Furnas, ou discordante com metassedimentos neoproterozóicos do embasamento da bacia. Costa et al. (1975) mediram a seção na Fazenda Água Cristalina, onde a Formação Ponta Grossa tem 40 metros de espessura, constituída de arenitos, folhelhos e siltitos

Não existem informações seguras do ambiente deposicional da Formação Ponta Grossa na Bacia dos Parecis. Entretanto, o conteúdo fossilífero (trilobita e braquiopodas) encontrados na Bacia do Paaraná, indicam um ambiente marinho raso, evidenciado também pela presença dos hofiomorfos, passando para ambiente mais profundo, com a deposição dos pelitos da porção superior desta formação.

FORMAÇÃO PIMENTA BUENO - CARBONÍFERO (Leal et al., 1978) Esta formação aflora na Fossa Tectônica de Rondônia (Siqueira,1989), localizada no extremo noroeste da Bacia dos Parecis (figura 2). A Formação Pimenta Bueno é constituída de folhelhos, arenitos, siltitos e conglomerados suportados pela matriz, como mostrados na figura 8.

O contato inferior da formação é com o embasamento cristalino e o contato superior é com a Formação Fazenda da Casa Branca, podendo ser observados a leste do centro de Cacoal. Segundo Siqueira (1989) a espessura da formação é de 761 metros.

Os folhelhos são de coloração marrom, micáceos, intercalados com siltito marrom ou arenitos claros. Os arenitos são marrons com pintas claras, têm granulometria média e são composto de quartzo, feldspato e muscovita; acamamento plano-paralelo e estratificações cruzadas tabular e acanalada são comuns. No centro de Rolim de Moura ripple marks foram encontradas. Os conglomerados suportados pela matriz são avermelhados, com seixos e boulders subarredondados de granitos, gnaisses e rochas básicas e angulosos de xistos e quartzitos. Seus diâmetros máximos são de 40 centímetros. Associados a esses conglomerados ocorrem siltitos com laminação plano-paralela, na qual existem grãos de areia e seixos dispersos, estes deformando a 


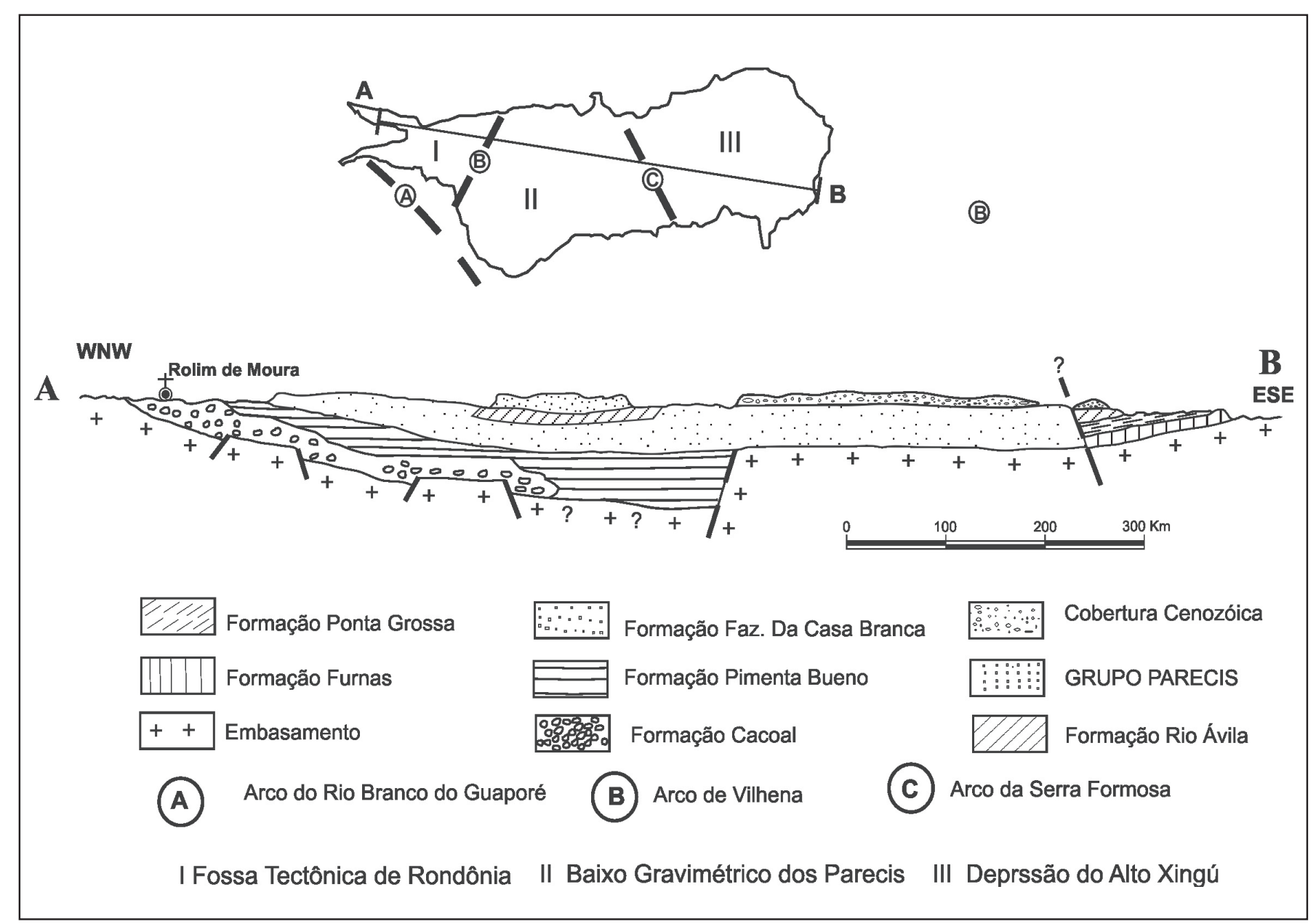

Figura 3 - Mapa geológico da Bacia dos Parecis

laminação (unidade dropstone).

Segundo Bahia \& Pedreira (1996), os folhelhos foram depositados em ambiente marinho raso, evidenciado pela presença de acritarcas do gênero Spheridium, identificados por Cruz (1980). As estruturas sedimentares dos arenitos sugerem sua deposição em ambiente fluvial, em canais tipo braided, com abundante suprimento de areia, a qual apresenta uma composição feldspática, indicando um clima desértico ou glacial. Seriam depósitos de outwash plain indicando o recuo definitivo das geleiras. A associação diamictito-unidade dropstone representado pelo conglomerado mais o siltito com seixos dispersos na laminação, segundo o modelo de Ojakangas (1985), é interpretado como evidência de clima glacial; os diamictitos correspondem ao tilito de alojamento, formado pela deposição de debris na base da geleira, ou muito provavelmente são depósitos de fluxo de detritos de front de geleira em ambiente subaquático; a unidade "dropstone" resulta da queda de clastos dos "icebergs" durante a deposição do siltito, em ambiente marinho.

FORMAÇÃO FAZENDA DA CASA BRANCA - NEOCARBONÍFERO-EOPERMIANO (Leal et al., 1978) Padilha et al. (1974) mapearam esta unidade em Vilhena e nos canais dos rios Arinos e Teles Pires como composta de conglomerados, arcóseos, grauvacas e pelitos, como fizeram Ribeiro Filho et al. (1975) no sul da bacia. Costa et al. (1975) reconheceram a formação na borda leste da bacia, composta de conglomerados, arenito e arenito siltoso com dropstone, depositados sobre a Formação Ponta Grossa.

Nos trabalhos de campo verificou-se que esta unidade aflo- ra inteiramente nas bordas norte e oeste Bacia dos Parecis. Na borda norte, ao longo da rodovia que liga Juína a Brasnorte, é constituída de arenito muito fino, argiloso, maciço, de cor marrom. Para o topo passa para arenito grosso, da mesma cor, maciço, feldspático. Sobrepondo este pacote arenoso ocorre uma camada de conglomerado de 2 metros de espessura, sustentado pela matriz arenosa, de cor marrom, com seixos de quartzo e granito, com diâmetros de até $5 \mathrm{~cm}$. Finalizando, no topo volta a aparecer o arenito muito fino descrito na base da seção.

Na borda oeste, na região de Vilhena, em sua seção-tipo descrita por Leal et al (1978), esta formação está representada por um arenito fino, argiloso, de cor creme, com estratificação planoparalela e cruzada tabular de grande porte, com suave mergulho para norte (Figura 9). Em detalhe o arenito apresenta uma bimodalidade dos grãos, diagnosticada pela laminação presente.

Os conglomerados nos quatro intervalos da figura 8 são polimíticos, no qual os clastos apresentam diâmetro máximo de 40 centímetros e são separados por camadas ou lentes de areia fina a grossa.

O contato inferior dessa formação é com a Formação Pimenta Bueno, sendo observado ao longo da rodovia BR-364. O contato superior é erosivo, tipo inconformidade, atestado pela quebra negativa de relevo, bem definida em imagem de satélite e na referida rodovia. A espessura da formação no centro da bacia é de 150 metros, adelgaçando para 40 metros na localidade de Porto dos Gaúchos (Padilha et al, 1974).

Considerando o ambiente deposicional da Formação Fazenda da Casa Branca, Padilha et al (1974) interpretaram como flúvio-lacustrino, em ampla planície de inundação. Entretanto, Si- 


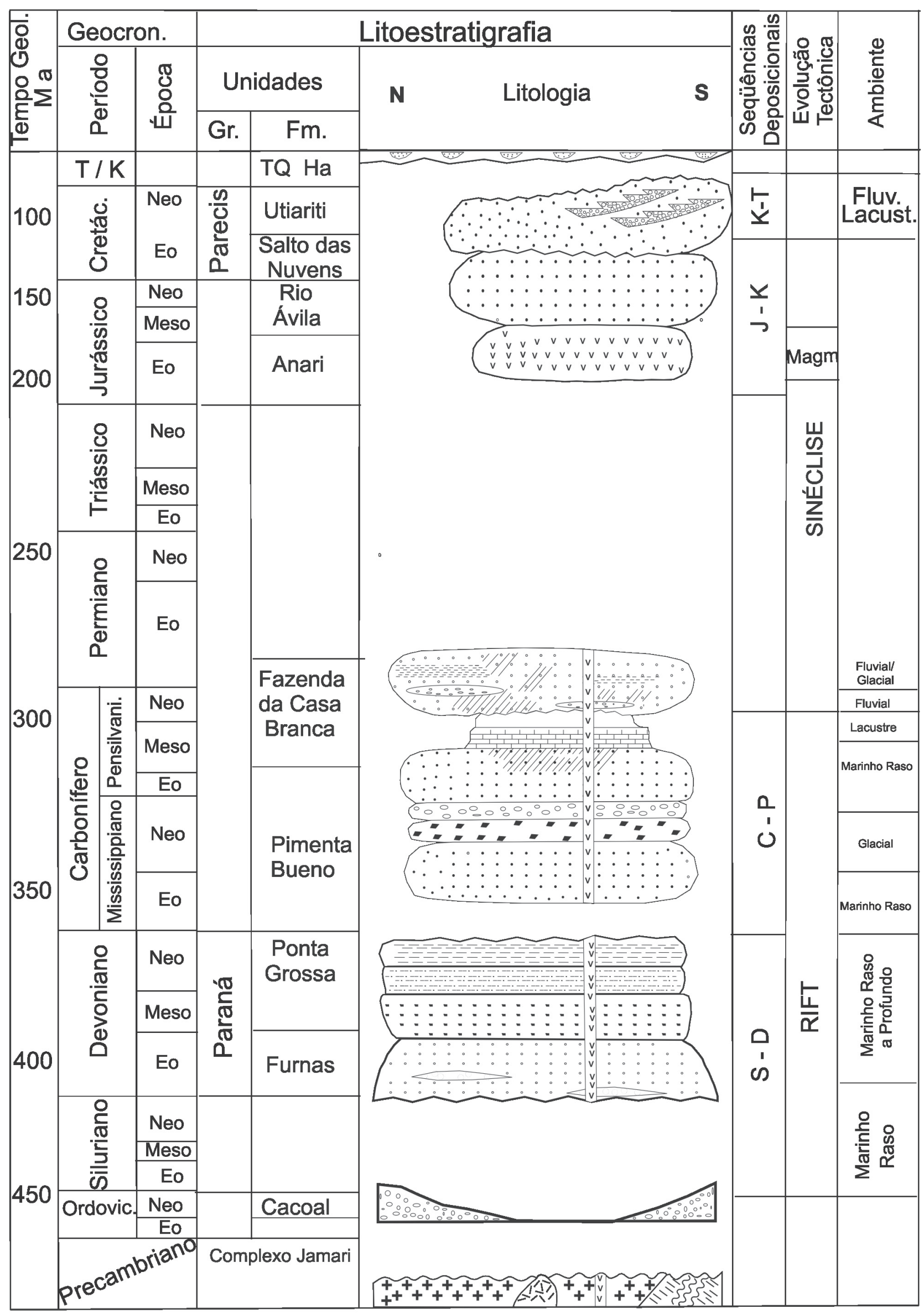


queira (1989) mencionou que Caputo (1984) interpretou como ambiente glacial ou periglacial. Segundo este autor, no ambiente periglacial os processos deposicionais envolvidos não são glaciais, mas são diretamente condicionados pela glaciação durante o período paraglacial. Depósitos glaciogênicos, caso da Formação Pimenta Bueno, representam períodos interglaciais (pulsos de aquecimento) ou pós glaciais, quando geleiras de base úmida se movimentam e retraem, depositando sedimentos. Períodos glaciais sensu strictu são sempre representados por hiatos/discordâncias, caso do Carbonífero Inferior nas bacias do Paraná e Parecis. Se imaginarmos o continente antártico no momento atual, há deposição localizada de sedimentos apenas nas bordas do mesmo. Na grande vastidão continental, há dezenas de milhões de anos, nada acontece, pois as geleiras, com base seca, aguardam um aquecimento global, condições para que ocorra o derretimento do gelo e conseqüente transporte e deposição de sedimentos.

FORMAÇÃO ANARI (Pinto Filho, 1977) / TAPIRAPUÃ - JURÁSSICO (Corrêa \& Couto, 1972) Este evento magmático, de composição básica, aflora no sudeste do Gráben do Colorado (figura 2), sob a denominação de Formação Anari (Pinto Filho et al. 1977), enquanto que a Formação Tapirapuã (Corrêa \& Couto, 1972), tem suas melhores exposições na serra homônima,

\begin{tabular}{|c|c|c|c|}
\hline 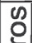 & Litologia & Descrição & Interpretação \\
\hline & $\mid 11$ & Dolomito & Depósito lacustrino \\
\hline & $\overline{-z}$ & Folhelho marrom e esverdeado & Depósito de prodelta \\
\hline & & Arenito maciço marrom & Planície deltaica \\
\hline & & Folhelho marrom & Depósito de prodelta \\
\hline & & $\begin{array}{l}\text { Arenito marrom com estratifica- } \\
\text { ção cruzada acanalada }\end{array}$ & $\begin{array}{l}\text { Canais distributários } \\
\text { em planície deltaica }\end{array}$ \\
\hline N & & $\begin{array}{l}\text { Folhelho marrom com } \\
\text { partes esverdeadas }\end{array}$ & Depósito de prodelta \\
\hline & & $\begin{array}{l}\text { Arenito marrom com } \\
\text { acamamento horizontal }\end{array}$ & Planície deltaica \\
\hline & 三五 & Folhelho marrom & Depósito de prodelta \\
\hline & & $\begin{array}{l}\text { Folhelho marrom, siltito marrom } \\
\text { e dolomito interacamadado }\end{array}$ & Frente deltáica \\
\hline & 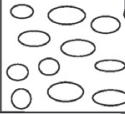 & $\begin{array}{l}\text { Conglomerado polimítico } \\
\text { suportado pela matriz }\end{array}$ & Leque aluvial \\
\hline
\end{tabular}

Figura 5- Coluna estratigráfica da Formação Cacoal

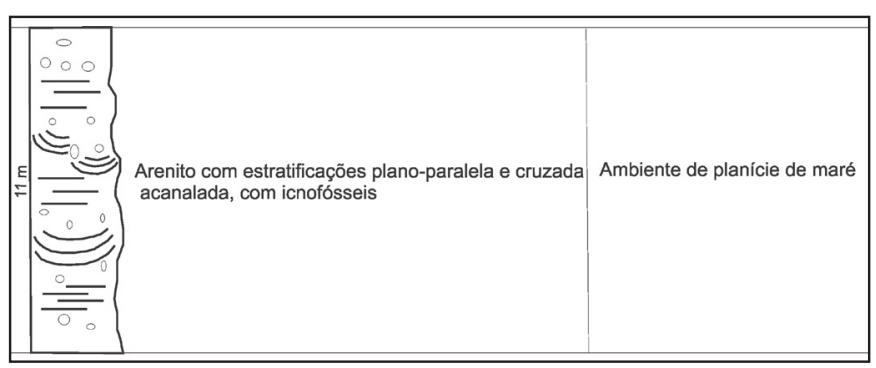

Figura 6- Coluna estratigráfica da Formação Furnas na Fazenda Sete de Setembro (baseada em Costa et al.,1975). próximo de Tangará da Serra (MT)

A Formação Anari é constituída de basaltos isotrópicos, com granulação fina a afanítica, coloração cinza-chumbo, tendo disjunção colunar como principal característica estrutural. Subordinadamente existem corpos de diabásios que são distinguidos pela sua granulação grossa e ausência de vidro vulcânico.

Pinto Filho et al. (1977), pela analogia com outras regiões assumiu a idade cretácica para esta formação, a qual foi correlacionada à Formação Serra Geral da Bacia do Paraná. A idade dos basaltos da Formação Anari, obtida pelo método K/Ar estão mostradas na Tabela 1.

O basalto da Formação Tapirapuã apresenta uma composição mineralógica e características gerais similares às rochas da Formação Anari. É também isotrópico, cinza-chumbo, de granulação afanítica, com estruturas amigdaloidais, disjunção colunar e esfoliação esferoidal. Esta unidade foi datada pelo método Ar/Ar por Marzoli et al.(1999) em 1980,8 Ma (Tabela 2).

FORMAÇÃO RIO ÁVILA - NEOJURÁSSICO/EOCRETÁCEO (Bizzi,2003) Esta formação aflora a norte de General Carneiro, no vale do rio Culuene e a noroeste de Vilhena, onde se encontra sua seção-tipo. No primeiro local, consiste de arenito vermelho, friável, com grãos arredondados, bem a mal selecionados, com intrusões de diabásios e lamprófiros. A noroeste de Vilhena, limitada por falhas, aflorando em escarpas, ocorrem arenitos cor de rosa, com granulometria fina a média, bem selecionados e arredondados, com expressiva bimodalidade (figura 10).

As principais estruturas sedimentares em ambos lugares são acamamentos cruzados cuneiformes, que no último local apresentam uma espessura de 20 metros no foreset.

A Formação Rio Ávila na Bacia dos Parecis tem numerosas evidências de origem eólica. Desde Ribeiro Filho et al.(1975) o acamamento cruzado é interpretado como eólico; esta interpretação foi confirmada nos trabalhos de campo e está embasada pelas observações feita a noroeste de Vilhena, onde a quebra negativa de relevo forma escarpas, nas quais aparece o arenito com estratificação cruzada de grande porte e expressiva bimodalidade dos grãos.

O contato inferior da formação é com a Formação Ponta Grossa a norte de General Carneiro; o contato superior se dá com os sedimentos cenozóicos e com a Formação Parecis. A espessura da Formação Rio Ávila foi estimada por Siqueira (1989) em 90 metros.

KIMBERLITOS Os kimberlitos do Cretáceo afloram em grupos de vários corpos a sudeste e noroeste da Bacia dos Parecis, ao longo de um arco (Schobbenhaus et al.,1984). Os corpos no

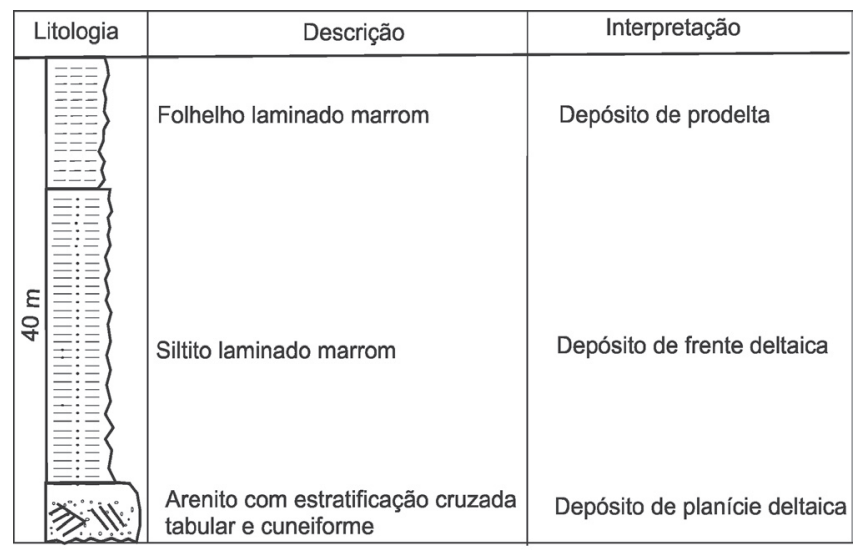

Figura 7- Coluna estratigráfica da Formação Ponta Grossa. 
sudeste da bacia, estão no Estado do Mato Grosso. São kimberlitos ígneos primários e sedimentos tipo caldeira, contendo xenólitos de arenito e do embasamento cristalino. O contato dos pipes kimberlíticos são zonas brechadas.

Os corpos a noroeste estão ambos nos estados do Mato Grosso e Rondônia, cortando o embasamento assim como as formações Fazenda da Casa Branca e Pimenta Bueno. Alguns desses corpos são diamantíferos (Schobbenhaus et al.,1984).

GRUPO PARECIS - CRETÁCEO (Oliveira, 1915) Este grupo aflora no setor sudoeste da Bacia dos Parecis, na área limitada pelo centro de Colorado do Oeste, Vilhena, Brasnorte e Alto Paraguai (figura 2). É constituído de conglomerado, arenito e pelitos (Figura 11).

Padilha et al. (1974) dividiu o Grupo Parecis, naquela época considerada como formação, em dois membros, chamando-os informalmente como eólico a porção inferior e aquoso a porção superior.

Posteriormente Barros et al. (1982) designaram de Formação Salto das Nuvens a porção inferior e Formação Utiariti a porção superior. O membro inferior de Padilha (1974) consiste de arenito fino a médio, apresentando intercalações de argilito e conglomerado. Acamamentos cruzados tipo cunha com um metro de altura e dezenas de metros de extensão são comuns (Barros \& Pastore Jr., 1974).

Os arenitos da porção superior no centro da bacia são brancos, cor de rosa, amarelos e cinzas, finos a médios, contendo camadas silicificadas com ripple marks preservadas (Padilha, 1974). No topo da formação os arenitos são silicificados, ou ortoquartzito, com camadas de arenito siltoso.

O contato inferior do Grupo Parecis é com os arenitos eólicos da Formação Rio Ávila. O contato superior é com a cobertura terciária.

A espessura da formação está entre 120 a 150 metros (Padilha, 1974).

FORMAÇÃO SALTO DAS NUVENS - Barros et al. (1982) No Estado do Mato Grosso, próximo à cidade de Tangará da Serra, Barros et al. (op.cit.), criaram a Formação Salto das Nuvens para designar os conglomerados, intercalados com lentes de

\begin{tabular}{|l|l|l|}
\hline \multicolumn{1}{|c|}{$\mid \begin{array}{l}\text { Descrição } \\
\text { Arenito com estratificação }\end{array}$} & \multicolumn{1}{|c|}{ Interpretação } \\
cruzada acanalada & $\begin{array}{l}\text { Dunaso 3D } \\
\text { Depósito de overbank }\end{array}$ \\
\hline
\end{tabular}

Figura 8- Coluna estratigráfica da Formação Pimenta Bueno na Região de Rolim de Moura (Bahia \& Pedreira, 1996). arenito vermelho, além de arenito bimodal, com estratificação cruzada de grande porte. A seção-tipo desta formação encontrase na Cachoeira Salto das Nuvens no rio Sepotuba, que representa a porção inferior do Grupo Parecis. Os sedimentos foram depositados em ambientes de leque aluvial e canal fluvial, com contribuição eólica.

Os conglomerados basais que afloram no sudoeste da bacia são polimíticos, mal selecionados, com clastos de gnaisses, quartzito, arenito, folhelho e ardósia (Barros \& Pastore Jr, 1974). Os seixos dos conglomerados da porção intermediária da formação são de arenito e quartzo; seus diâmetros estão em torno de 30 centímetros.

Silva et al (2003) posicionaram esta unidade no Cretáceo Médio a Superior embasados na ocorrência de fósseis de Mesosuchidae (Notosuchidae), répteis crocodilomorfos de hábito terrestre, de ocorrência comum em rochas sedimentares do Cretáceo em toda América do Sul.

FORMAÇÃO UTIARITI - Barros et al. (1982) A porção superior do Grupo Parecis, Barros et al. (1982) designaram de Formação Utiariti, correspondendo as partes mais elevadas do Planalto dos Parecis.

Os arenitos que compõem esta unidade ocorrem nas corredeiras do Rio Papagaio, tendo um contato gradativo com a unidade inferior. São rochas com cores variadas, desde amarela, roxa a avermelhada, compostas essencialmente de quartzo e feldspato. São maciças ou localmente apresentando estratificação plano-paralela ou cruzada de pequeno porte. A granulometria varia de fina a média, com ocorrência de seixos nas porções basais.

$\mathrm{Na}$ estrada entre Colorado e Vilhena, a Formação Utiariti é composta de arenitos e folhelhos ou arenito argiloso (figura 11). Os arenitos são bimodais, com seixos dispersos e grandes acamamentos cruzados tipo cunha. Na seqüência intermediária, $\mathrm{o}$ arenito tem numerosos canais preenchidos por conglomerados com mais de sete metros de largura e um metro de profundidade. Adicionalmente, existem lentes de argilito. No topo da seqüência, argilito e arenito argiloso exibem intercalações lateralmente persistentes de arenito com estratificação cruzada de grande porte.

Padilha et al. (1974) interpretaram este membro inferior da

\begin{tabular}{|l|l|l|}
\hline \multicolumn{1}{|c|}{ Descrição } & \multicolumn{1}{|c|}{ Interpretação } \\
\hline
\end{tabular}

Figura 9 - Coluna estratigráfica da Formação Fazenda da Casa Branca (segundo Bahia \& Pedreira, 1996). 
Bacia dos Parecis como eólico. Esta interpretação está embasada na intercalação de argilito e conglomerado desse membro, que pode corresponder a depósitos de lagos rasos e planícies de areia com seixos das áreas interdunas; as dunas são representadas pelas camadas de foreset cruzado de grande porte.

Os conglomerados que preenchem os canais da seqüência intermediária, são interpretados como depósitos de lag e a seqüência, como depositada por correntes efêmeras de alto gradiente. A parte superior da seqüência sugere a presença de uma área onde os lagos de interdunas são repetidamente preenchidos pela migração das dunas. $\mathrm{O}$ ambiente deposicional do membro superior da Formação Parecis foi interpretado por Padilha et al. (1974) como fluvial-lacustrino; as ripple marks preservadas nas camadas de sílex, indicam deposição em águas rasas, possivelmente nas margens de um lago fechado. Os seixos do conglomerado são provavelmente derivados do membro inferior.

COBERTURA INCONSOLIDADA Esta cobertura, de idade terciária/quaternária, aflora continuamente na porção leste da bacia, na parte central, e parcialmente sobre a Formação Parecis. Consiste de sedimentos arenosos, siltosos e areno-siltosos, além de lateritas (Schobbenhaus et al., 1981). Localmente contém cascalho.

PALEOGEOGRAFIA E CORRELAÇ̃̃O COM OUTRAS BACIAS PALEOZÓICAS INTERIORES A sedimentação na Bacia dos Parecis possivelmente iniciou no Neo-Ordoviciano, começando com a sedimentação, durante a fase rifte da bacia, com a Formação Cacoal na Fossa Tectônica de Rondônia e da Formação Furnas, no extremo leste da bacia, na Depressão do Alto Xingu. Esta sedimentação continental e litorânea, respectivamente, passa gradativamente para uma sedimentação marinha, com a deposição dos pelitos da Formação Ponta Grossa. Representa uma inundação progressiva da plataforma no Eodevoniano, atingindo o pico em $440 \mathrm{Ma}$, correspondendo a um ciclo transgressivo-regressivo, que na Bacia do Paraná constitui a Superseqüência Paraná de Milani (1997).

O ambiente deposicional era caracterizado por um clima árido, onde houve deposição dos sedimentos em leques aluviais, deltas e planície de maré, compondo a fase inicial de preenchimento do rifte, com formação de fácies próximo das margens iniciais da bacia, que não aparecem na porção central da mesma. A incursão marinha no rifte teria ocorrido de leste para oeste, condicionada à formação do sistema que compõe a Fossa Tectônica de Rondônia.

Segundo Milani (op.cit.), na Bacia do Paraná a Formação Furnas é composta na base por arenito e conglomerado, encobertos por um arenito médio a grosso, com estratificação cruzada de várias naturezas. No topo ocorre arenito fino e siltito argiloso, com estruturas típicas de planície de maré. O arranjo vertical dessa formação é indicativo de uma transgressão marinha ocorrida na Bacia do Paraná no início do Devoniano (Figura 12).

Esta sedimentação continental e litorânea, respectivamente, passa gradativamente para uma sedimentação marinha, com a deposição dos pelitos da Formação Ponta Grossa. Representa uma inundação progressiva da plataforma no Eodevoniano, atingindo o pico em $440 \mathrm{Ma}$, correspondendo a um ciclo transgressivo-regressivo, que na Bacia do Paraná constituí a Superseqüência Paraná de Milani (1997).

A deposição dos sedimentos da Formação Ponta Grossa ocorreu em ambiente plataformal onde a influência marinha suplantou os processos deposicionais dos sistemas costeiros e transicionais da Formação Furnas

Portanto, a Formação Cacoal representa a porção continental da seqüência sedimentar inicial da Bacia dos Parecis, passando pelos sedimentos costeiros da Formação Furnas, mesmo não sendo observado nenhum registro em afloramento dessa passagem, até completar a seqüência com os sedimentos marinhos da Formação Ponta Grossa.

Na Bacia do Parnaíba, a Formação Itaim (Caputo,1984), correlata da Formação Maecuru da Bacia do Amazonas, é composta de uma intercalação de arenito, folhelho e siltito, indicando também uma transgressão marinha ocorrida na Bacia do Parnaíba durante o Devoniano Inferior.

Segundo Góes \& Feijó (1994), a Formação Itaim corresponde à base do Grupo Canindé, o qual representa a seqüência deposicional devoniana da Bacia do Parnaíba, correspondente à maior transgressão marinha ocorrida nesta bacia, cuja inundação máxima é representada pelos folhelhos Pimenteiras com bons índices para rocha geradora de hidrocarbonetos.

A fase transicional de rifte para sinéclise na Bacia dos Parecis (Fig.12), foi marcada por profundas modificações climáticas. Nestas condições é que foram depositadas as formações glaciogênicas Pimenta Bueno e fluvial (ou periglaciogênica) Fazenda da Casa Branca. Estas unidades constituem o pacote permo-carbonífero da Bacia dos Parecis correlacionado com a Superseqüência Gondwana I de Milani (1997) na Bacia do Paraná.

Após pico da glaciação cujo registro estratigráfico é o hiato erosional/não deposicional do Eocarbonífero, esta fase transicional é caracterizada inicialmente por invasão marinha e aumento progressivo na batimetria da Fossa Tectônica de Rondônia, onde ocorre a deposição dos sedimentos da Formação Pimenta Bueno. Sob condições ainda glaciais, a deposição ocorre durante o Carbonífero em ambiente fluvial, deltaico, lacustrino e marinho raso.

O pacote sedimentar contém, da base para o topo, depósitos fluviais de arenitos com estratificações cruzadas, interestratificados com folhelho marrom micáceo. Na porção intermediária aparecem os depósitos com influência glacial, com diamictitos, varvitos, siltitos e pelitos com seixos pingados (unidade dropstone).

Na porção superior ocorre uma intercalação de arenito fino, siltito e argilito, capeada por calcário dolomítico, evidenciando uma diminuição na profundidade da água do mar e retorno às condições áridas (Siqueira, 1989).

Este período glacial está representado também na Bacia do Paraná pelo Grupo Itararé, do qual faz parte a Formação Lagoa Azul, relacionada ao Neocarbonífero e correlata da Formação Pimenta Bueno. É constituída por um pacote arenoso inferior, sobreposto por folhelho e diamictito. Estes sedimentos recobrem uma superfície erosiva que limita o topo do Grupo Paraná, relacionada à Orogenia Eo-Herciniana, a qual ocorreu associada ao desenvolvimento de calotas de gelo, resultando em hiato expressivo na estratigrafia da bacia.

A Orogenia Eo-Herciniana afetou também as bacias do Parnaíba e Solimões, marcada por hiatos na estratigrafia dessas bacias, com retomada da sedimentação no Neocarbonífero, representada pelas Formações Piauí e Juruá, respectivamente. Entretanto, as condições climáticas são diferentes das atuantes durante a deposição dos sedimentos da formação Pimenta Bueno na Bacia dos Parecis. Representam depósitos arenosos, com eventuais ocorrências de conglomerado, folhelho e calcário, depositados em ambiente fluvial, litorâneo e desértico, sob forte aridez.

A Formação Fazenda da Casa Branca, proposta por Caputo (1984), foi correlacionada por Siqueira (1989) com a porção superior do Grupo Itararé da Bacia do Paraná e com a Formação Pedra de Fogo da Bacia do Parnaíba, ambas de idade permiana.

Costa et al.(1975) registraram a presença de restos de planta silicificada do Gênero Psaronius. Os arenitos, siltitos, argilitos, diamictitos e conglomerados da Formação Fazenda da Casa Branca, depositados em ambiente periglacial, segundo estes autores, podem ser correlacionados com a Formação Aquidauana da Bacia do Paraná, relacionada ao Stephaniano por Daemon 
Tabela 1- Idades K/Ar na Formação Anari

\begin{tabular}{|c|c|c|}
\hline Idade & (Ma) & AUTORES \\
\hline $208 \pm 14$ & Jurássico Inferior & Pinto Filho et al., 1977 \\
\hline $178 \pm 3$ & Jurássico & Santos \& Oliveira, 1980 \\
\hline $147 \pm 6$ & Jurássico Superior & Santos \& Oliveira, 1980 \\
\hline $111 \pm 8$ & Cretáceo & Santos et al., 1977 \\
\hline
\end{tabular}

Tabela 2-Idades K/Ar e Ar/Ar da Formação Tapirapuã

\begin{tabular}{|c|c|c||}
\hline Idades & (Ma) & AUTORES \\
\hline $112 \pm 3 \mathrm{~K} / \mathrm{Ar}$ & Cretáceo & Minioli et al., 1971 \\
\hline $198 \pm 8 \mathrm{Ar} / \mathrm{Ar}$ & Jurássico & Marzoli et al., 1999 \\
\hline
\end{tabular}

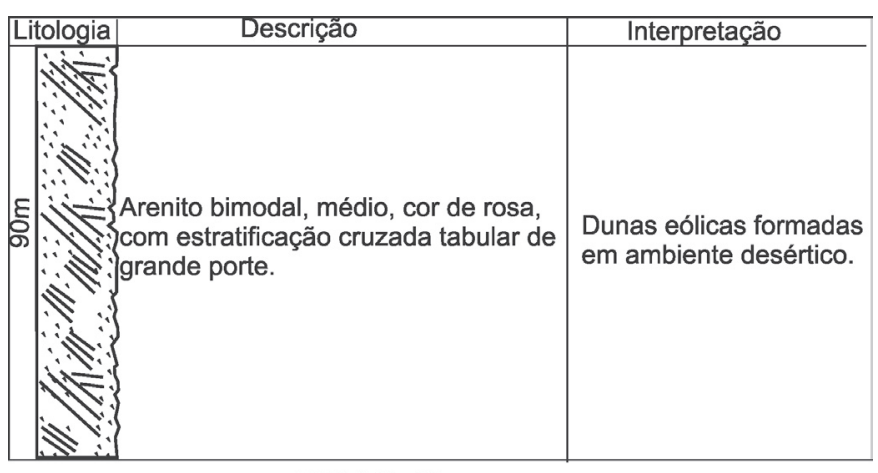

Figura 10 - Coluna estratigráfica da Formação Rio Ávila.

\& Quadros (1970). Esta correlação já havia sido proposta por Pinto Filho et al. (1977), com base na similaridade litológica e na presença de restos de plantas relacionadas ao Carbonífero Superior, conforme registrado na Bacia dos Parecís por Costa et al.(1975) através da caracterização da presença de restos de planta silicificada do Gênero Psaronius.

Embora correlacionáveis temporalmente, as formações Fazenda da Casa Branca da Bacia dos Parecis e Pedra de Fogo da Bacia do Parnaíba se depositaram em contextos paleoclimáticos distintos. Enquanto a primeira representa depósitos periglaciais, a segunda é caracterizada pela presença de sílex, calcário e arenito fino intercalado, interpretados como depositados em ambientes de mares rasos a litorâneos, com planícies de sabkha.

$\mathrm{Na}$ Bacia do Solimões a Formação Fonte Boa, proposta por Caputo (1984) para designar o Permiano Superior desta bacia, com base nas datações em palinomorfos de Daemon \& Contreiras (1971), é constituída de folhelho e siltito, intercalados com arenito muito fino, depositados em ambiente continental desértico. Esta formação pode ser perfeitamente correlacionada com a Formação Pedra de Fogo da Bacia do Parnaíba. Entretanto, correlaciona-se apenas temporalmente com a Formação Fazenda da Casa Branca em função do contraste de condições climáticas e deposicionais.

Durante o Mesozóico, entre a orogênese Gonduanide e a Tectônica Juruá, a região amazônica foi novamente afetada por outro evento extensional. Este evento ocorreu após um período de soerguimento das bacias dos Parecis, Solimões, Amazonas e Parnaíba, sendo evidenciado por hiato na estratigrafia dessas ba-

\begin{tabular}{|c|c|c|c|}
\hline Metros & Litologia & Descrição & Interpretação \\
\hline 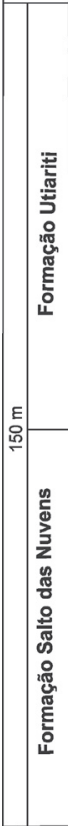 & 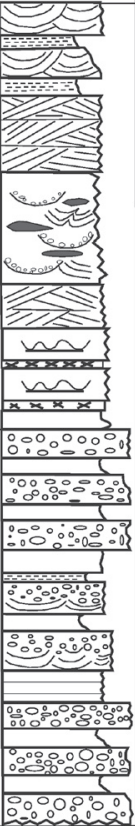 & $\begin{array}{l}\text { Arenito bimodal com estratificação } \\
\text { cruzada acanalada cuneiforme, } \\
\text { interestratificado com argilito } \\
\begin{array}{l}\text { Arenito bimodal com estratificação } \\
\text { cruzada tabular de grande porte. }\end{array} \\
\text { Arenito com estratificação cruzada } \\
\text { acanalada com níveis de seixos na } \\
\text { base e lentes de argilito. } \\
\text { Arenito bimodal com estratificação } \\
\text { cruzada tabular de grande porte. } \\
\begin{array}{l}\text { Arenito fino com niveis de chert e } \\
\text { marcas onduladas }\end{array}\end{array}$ & $\begin{array}{l}\text { Lagos interdunas invadidos } \\
\text { por dunas migrantes. } \\
\text { Dunas tipo seif ou partes de } \\
\text { dunas tipo barcanas ou } \\
\text { estrelas. } \\
\text { Fácies fluvial; avulsão do } \\
\text { canal indica baixa } \\
\text { subsidência. } \\
\text { Dunas eólicas tipo seif } \\
\text { Lagos interdunas }\end{array}$ \\
\hline
\end{tabular}

Figura 11 - Coluna estratigráfica do Grupo Parecis

cias. Este evento extensional provocou uma nova subsidência, compensada pela deposição de sedimentos eólicos e derrames de rochas vulcânicas alcalinas, em ambiente continental, sob condições de clima árido, num amplo deserto gondwânico. Na Bacia dos Parecis está representado pelas formações Anarí/Tapirapuã e Rio Ávila, respectivamente.

Pinto Filho et al.(1977), com base nas semelhanças litológica e estrutural, correlacionou as formações Rio Ávila e Anarí/Tapirapuã com as formações Botucatu e Serra Geral, na Bacia do Paraná, que constituem a Superseqüência Gondwana III de Milani (1997). Entretanto, esta correlação torna-se incompatível devido à idade de $200 \mathrm{Ma}$ obtida, pelo método Ar/Ar por Marzoli (1999) em rochas da Formação Tapirapuã, não sendo ainda reconhecido nenhum evento magmático dessa idade na Bacia do Paraná.

Na Bacia do Solimões, apesar da ausência de sedimentos eólicos relacionados aos períodos Jurássico e Cretáceo, ocorre o Magmatismo Penatecaua (Issler,1974), ocorrido entre a Orogenia Tardi-Herciniana e o Tectonismo Juruá. Apresenta-se intercalado, através de soleiras, nas rochas paleozóicas da bacia. Este magmatismo foi relacionado ao Eojurássico através da idade de 190 \pm 20 obtida por Mizusaki et al. (1992).

$\mathrm{Na}$ Bacia do Parnaíba, entretanto, a correlação é perfeitamente compatível com os basaltos de idade Juro-Triássica, toleíticos, da Formação Mosquito (Aguiar 1969) e com os arenitos eólicos da Formação Sambaíba (Plummer 1946).

Prosseguindo com a subsidência da bacia até o Cretáceo Superior, ainda em fase sinéclise, ocorre a deposição dos sedimentos flúvio-lacustres do Grupo Parecis (Oliveira,1915). Esta formação é correlacionada por Siqueira (1989) com o Grupo Bauru da Bacia do Paraná e formações Grajaú/Codó e Itapecurú da Bacia do Parnaíba. A correlação com o Grupo Bauru é completa, pois, além da contemporaneidade, o mesmo é constituído de depósitos flúvio-aluviais, com contribuição eólica, depositados em fase sinéclise da Bacia do Paraná. Entretanto, na Bacia do Parnaíba, o sistema Grajaú-Codó-Itapecurú, depositou-se, respectivamente, em ambientes fluvial-marinho restrito-fluvial, diferenciando-se do Grupo Parecis pela presença da incursão marinha intermediária Codó. 
Ruy B. C. Bahia et al.
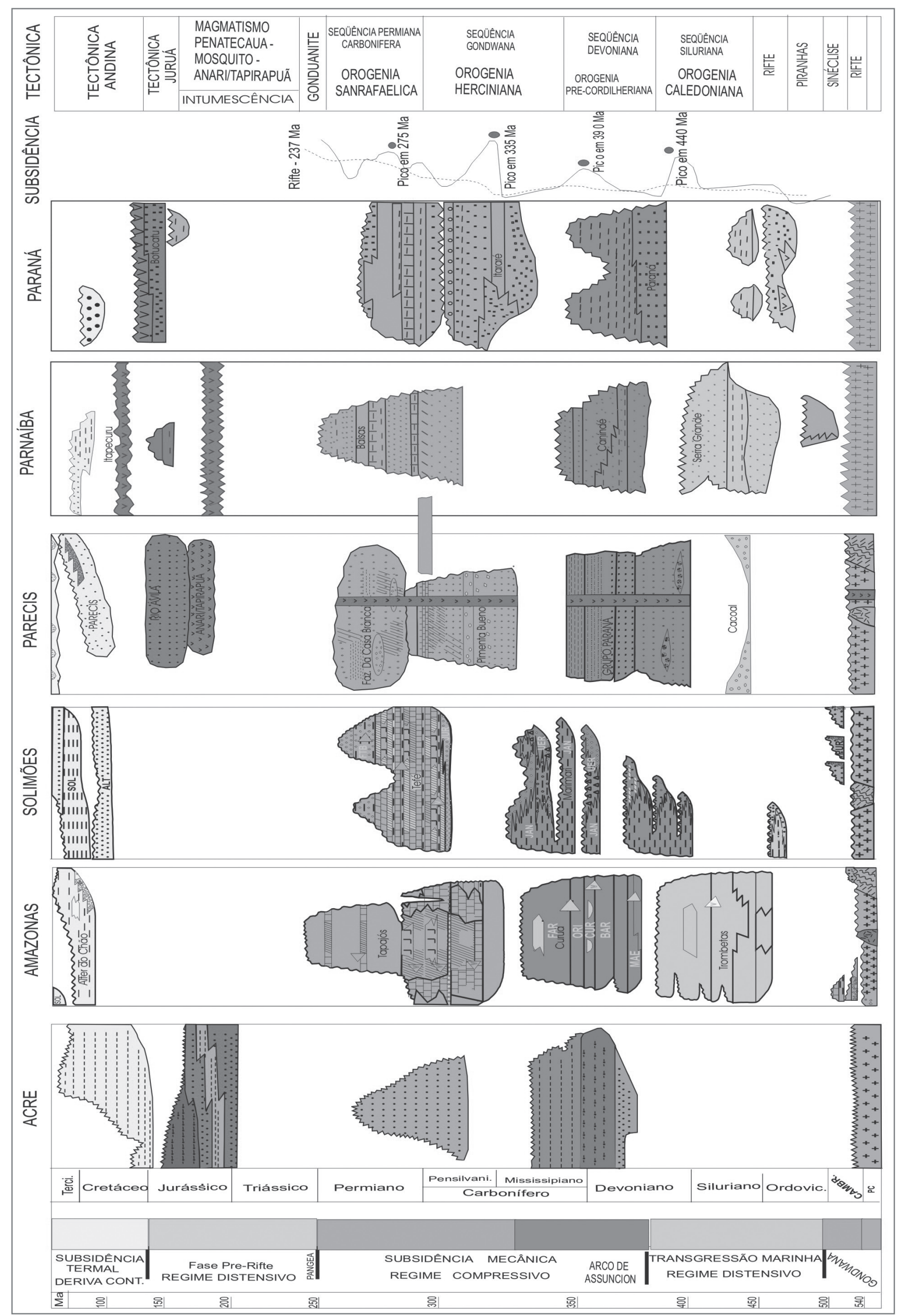

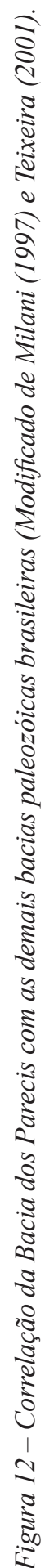


Na Bacia do Solimões a Formação Alter do Chão, segundo Caputo (1984), designa sedimentos fluviais e lacustres, depositados em clima tropical úmido, em fase sinéclise da bacia. Estão relacionados ao Cretáceo Superior por correlação com a Bacia do Amazonas, na qual foram encontrados dentes de dinossauros. Portanto, a correlação com a Formação Parecis é aceitável em termos litológicos, ambiência deposicional e contexto geotectônico.

Não existem evidências de forte modificação da Bacia dos
Parecis por eventos pós-deposicionais. Entretanto, durante o Cenozóico, o soerguimento da Cordilheira Andina, teve reflexo na bacia. Nesta época ocorreu o soerguimento do Arco do Rio Guaporé, que separa a bacia da Depressão Sub-andina e a sedimentação cenozóica foi restringida à Bacia dos Parecis, sendo desenvolvida em uma crosta laterítica desmantelada, a qual limitava o topo da Formação Parecis. Esta sedimentação pode ser correlacionada com a Formação Solimões da bacia homônima e Formação Cachoeirinha da Bacia do Paraná.

\section{Referências}

Aguiar G.A. 1969. Bacia do Maranhão: geologia e possibilidades de petróleo. PETROBRÁS, Belém, Relatório Interno.

Almeida F.F.M.1983. Relações tectônicas das rochas alcalinas mesozóicas da região meridional da Plataforma Sul-Americana. Revista Brasileira de Geociências, 13:139-158.

Araújo V.A., Costa J.F.G., Montes A. de S.L., Pereira A.D.C. 1975. Projeto Manissauá-Missu. Reconhecimento geológico. DNPM/CPRM, Goiânia, v.1

Bahia R.B.C \& Pedreira A.J.1996. Depósitos glaciogênicos da Formação Pimenta Bueno (Carbonífero) na região de Rolim de Moura, sudeste de Rondônia. A Terra em Revista, 1:24-29.

Bahia R.B.C., Quadros M.L. do E.S., Pedreira A.J.1996. As coberturas sedimentares fanerozóicas da região sudeste de Rondônia. In: SBG, Congresso Brasileiro de Geologia, 39, Anais, p. 299-302.

Barbosa O., Andrade Ramos J.R., Gomes F.A., Hembold, R. 1966. Geologia estratigráfica, estrutural e econômica da área do Projeto Araguaia. Rio de Janeiro, DNPM/DGM, Monografia 19, 94 p.

Barros A.M. \& Pastore Junior W.P. 1974. Projeto Alto Guaporé. Relatório final. Folha Tangará da Serra-SD.21-Y-B. DNPM/CPRM, Goiânia.

Barros A.M., Silva R.H. da, Cardoso O.R.F.A., Freire F. A., Souza Junior J.J. de, Rivetti M., Luz D.S. da, Palmeira R.C. de B., Tassinari C.C.G. 1982. Geologia. In: DNPM. Projeto Radambrasil. Folha SD. 21 Cuiabá; geologia, geomorfologia, pedologia, vegetação e uso potencial da terra. Rio de Janeiro, Levantamento de Recursos Naturais, 26, p. 25-192.

Bizzi L.A., Schobbenhaus C., Vidotti R.M., Gonçalves J.H. (Eds.) 2003. Geologia tectônica e recursos minerais do Brasil: texto, mapas \& SIG. CPRM, Brasília, 673 p.

Braga L.F.S. \& Siqueira L.P. 1996. Three dimensional gravity modeling of the basement topography beneath Parecis Basin, Brazil, constrained by spectral estimates of depth to magnetic sources. In: CONNEXPO/ARPEL, Latin American Petroleum Congress, 5, Atas, 8 p.

Caputo M.V. 1984. Stratigraphy, tectonics, paleoclimatology and paleography of the northern basins of Brazil. Tese de Doutoramento, University of California, $533 \mathrm{p}$.

Ciguel J.H., Pedreira A.J., Góis J.R.1996. Os icnofósseis da localidade de Sítio Cercado, Brasil-Formação Furnas (Siluro-Devoniano), flanco oriental da Bacia do Paraná. In: Simpósio Sul Americano do Siluro Devoniano, Anais, p. 319-335.

Correa J.A. \& Couto E.A. do. 1972. Projeto aluviões diamantiferos de Mato Grosso. DNPM/CPRM, Goiânia, Relatório de Arquivo Técnico da DGM, 1940, Relatório Final, 2v.

Costa S.A.G., Fragomeni P.R.P., Fragomeni M.G. 1975. Projeto Serra do Roncador. Reconhecimento geológico. DNPM/CPRM, Goiânia, Relatório final, $3 \mathrm{v}$.

Cruz N.M.C. 1980. Palinologia de sedimentos paleozóicos do Território Federal de Rondônia. In: SBG, Congresso Brasileiro de Geologia,31, Anais. p. 3041-3048.

Daemon R.F. \& Contreiras C.J.A. 1971. Zoneamento palinológico da Bacia do Amazonas. In: SBG, Congresso Brasileiro de Geologia, 25, Anais, p. 79-88.

Daemon R. \& Quadros L.P. de. 1970. Bioestratigrafia do Neoproterozóico da Bacia do Paraná. In: SBG, Congr. Bras. Geol., 24, Anais, p. 359-412.

Figueiredo A.J. de A., Barros A.M., Eulálio Filho A., Rodrigues A.P., Barreto B.F., Pimentel G.B., Couto J.G.P., Reischl J.L., Costa S.A.G.,
Resende Filho S.T., Pastore Júnior W.P., Ribeiro Filho W. 1974. Projeto Alto Guaporé. CPRM, Goiânia, Relatório Final,11 v.

Freitas A.F. de 1977. Projeto Presidente Hermes. CPRM, Porto Velho, Relatório Final de Pesquisa, 1v.

Frostick L.E. \& Reid I. 1987. Tectonic control of desert sediments in rift basins ancient and modern. In: L.E. Frostick \& I. Reid (eds.) Desert Sediments: ancient and modern. Oxford, Geological Society Special Publication, n. 35, Blackwell, pp.: 53-68.

Góes A.M.O. \& Feijó F.J. 1994. Bacia do Parnaíba. Boletim de Geociências da PETROBRÁS, 8(1):57-67.

Gonzaga de Campos L.F. 1889. Seção geológica. In: São Paulo. Comissão Geográfica e Geológica. São Paulo, J. Skeller, Relatório 1889, pp.: 21-24.

Issler R.S. 1974. Esboço geológico-tectônico do Craton do Guaporé. In: SBG. Congr. Bras. Geol., 28, Resumo das Comunicações, p. 659665 .

Kingston D.R., Dishroon C.P., Williams P.A.1983. Global basin classification system. American Association of Petroleum Geologists Bulletin, 67:2175-2193.

Klein G.D. 1995. Intracratonic basins. In: C.J. Busby \& R.V. Ingersoll (eds.) Tectonics of sedimentary basins. Blackwell Science, Cambridge, pp.: 459-478.

Leal J.W., Silva G.F., Santos D.B. dos, Teixeira W., Lima M.I.C. de, Fernandes A.C., Pinto A. do C. 1978. Geologia. In: DNPM. Folha SC. 20 Porto Velho; geologia, geomorfologia, pedologia, vegetação e uso potencial da terra. Projeto Radambrasil. Rio de Janeiro, Levantamento de Recursos Naturais, 16, p. 17-184.

Lima P.F.C. 975. Projeto Apiacás-Caiabís. Reconhecimento geológico. DNPM/CPRM, Goiânia, Relatório final integrado, v. 1.

Lobato F.P.N.S., Appel L.E., Godoy M.C.F.T. de, Ritter J.E. 1966. Pesquisa de cassiterita no Território Federal de Rondônia. DNPM/ DFPM, Rio de Janeiro, Boletim 125, Relatório Final, 209 p.

Marzoli A., Renne P.R., Piccirillo E.M., Ernesto M., Bellieni G., De Min A. 1999. Extensive 200-million-year-old continental flood basalts of the Central Atlantic Magmatic Province. Science, 284:616-618.

Milani E.J. 1997. Evolução tectono-estratigráfica da Bacia do Paraná e seu relacionamento com ageodinâmica fanerozóica do Gondwana Sul-Ocidental. Tese de Doutoramento, Universidade Federal do Rio Grande do Sul, Porto Alegre, $255 \mathrm{p}$.

Minioli B., Ponçano W.L., Oliveira S.M.B. 1971. Extensão geográfica do vulcanismo basáltico do Brasil meridional. Anais da Academia Brasileira de Ciências, 43:433-437.

Mizusaki A.M.P., Wanderley Filho J.R., Aires, J.R. 1992. Caracterização do magmatismo básico das bacias do Solimões e do Amazonas. PETROBRÁS, Rio de Janeiro, Relatório Interno.

Neves B.B.B, Brito Neves B.B., Cordani A., Thomaz Filho R.A. 1984 Influence of basement structures on the evolution of the major sedimentary basins of Brazil: a case of tectonic heritage. Journal of Geodynamics, 1(3):495-510.

Neves B.B.B. \& Cordani U.G. 1991. Tectonic evolution of South America during the late Proterozoic. Precambrian Research, 53:23-40.

Neves B.B.B. 1995. Crátons e Faixas Móveis. Boletim IG-USP Série Didática, 7:1-187.

Ojakangas R.W.1985. Evidence of early Proterozoic glaciation: the dropstone unit-diamictite association. Geological Survey of Finland Bulletin, 331:51-72.

Oliveira E.P.1912. O terreno devoniano do Sul do Brasil. Anais da Esco- 
la de Minas, 14:31-41.

Oliveira E.P. 1915. Reconhecimento geológico do noroeste de Mato Grosso. Expedição Científica Roosevelt-Rondon. Comissão Linhas Telegráficas Estratégicas de Mato Grosso ao Amazonas, Rio de Janeiro, Publicação, 50:1-82.

Padilha A.V., Montes A. de S.L., Barros C.A.F. de, Lemos D.B., Frota G.B., Luz J. da S., Moreira J.M.P., Moreno J.J.P., Montes M.L., Menezes Filho N.R., Cardoso O.R.F.A., Lima P.F.C., Almeida W.J. de, Abreu Filho W., Silveira W.P., Santana W.R.R. 1974. Projeto Centro-Oeste de Mato Grosso. DNPM/CPRM, Goiânia, Relatório final, v. 1.

Pedreira A.J. 1998. Sistemas deposicionais e estratigrafia da Bacia dos Parecis no Estado de Rondônia. CPRM, Salvador, 32 p. (Relatório inédito).

Pinto Filho F.P., Freitas A.F. de, Melo C.F. de, Romanini S.J. 1977. Projeto Sudeste de Rondônia. DNPM/CPRM, Porto Velho, Relatório final, $4 \mathrm{v}$.

Plummer F.D. 1946. Geossinclineo do Parnaíba. Conselho Nacional do Petróleo, Rio de Janeiro.

Reed L.E., 1993. The application of geophysics to exploration for diamonds. In: K. Dunne \& B. Grant (eds.) Mid-continent diamonds. Symposium Volume, Geological Association of Canada, pp.: 21-26.

Ribeiro Filho W., Luz J.S., Abreu Filho W. 1975. Projeto Serra Azul. Reconhecimento geológico. DNPM/CPRM, Goiânia, Relatório final, v. 1

Santos J.O.S. \& Oliveira J.R. 1980. Principais associações máficas não metamorfizadas da Plataforma Amazônica. In : SBG, Congr. Brasil. Geol., 31, Anais, p. 2253-2262.

Santos R.D.B., Pitthan, J.H.L., Barbosa E.S., Fernandes C.A.C., Tassinari C.C.G., Campos D. de A.1979. Geologia. In: DNPM. Folha SD.20 Guaporé; geologia, geomorfologia, vegetação e uso potencial da terra. Rio de Janeiro, Projeto RADAMBRASIL, Levantamento de Recursos Naturais19, p. 21-123.

Scandolara J.E. (org.) 1997. Mapa geológico do Estado de Rondônia. Escala 1:1.000.000. CPRM/REPO, Porto Velho. (Versão preliminar).

Schobbenhaus C., Campos D. De A., Derze G.R., Asmus H.E. 1981. Mapa geológico do Brasil e da área oceânica adjacente incluindo depósitos minerais. Escala 1:2.500.000. Brasília, MME/DNPM,

Schobbenhaus C., Campos D. de A., Derze G.R., Asmus H.E. (eds.) 1984. Geologia do Brasil; texto explicativo do mapa geológico do Brasil e da área oceânica adjacente incluindo depósitos minerais. Brasília, MME/DNPM, $501 \mathrm{p}$

Sengor A.M.C. 1995. Sedimentation and tectonics of fossil rifts. In: C.J. Busby \& R.V. Ingersoll (eds.) Tectonics of sedimentary basins. Cambridge, Blackwell Science, pp.: 53-117.

Siqueira L.P. 1989. Bacia dos Parecis. Boletim de Geociências da Petrobrás, 3:3-16.

Siqueira L.P. \& Teixeira L.B.1993. Bacia dos Parecis: nova fronteira exploratória da Petrobrás. In: SBGeof., Congr. Intern. Soc. Bras. Geof.,3, Resumos Expandidos, p. 168-170.

Soeiro R.S. 1981. Projeto Prospecção de Carvão Energético em Rondônia. DNPM/CPRM, Porto Velho, Relatório final.

Teixeira L.B. 2001. Evidência geofísica de rifts precursores nas Bacias Paleozóicas do Amazonas, Paraná, Parecis, Parnaíba, Solimões e Alto Tapajós. In: PETROBRÁS-CENPES, Workshop Correlação de Seqüências Paleozóicas Sul-Americanas, Atas, p.1-8.

Manuscrito AE034

Aprovado em 8 de novembro de 2006 